\title{
POTENTIALLY ASSOCIATED FACTORS WITH IRRITABLE BOWEL SYNDROME AMONG MEDICAL AIN SHAMS UNIVERSITY STUDENTS
}

\author{
Wesam Ahmed Ibrahim*, Doaa Zakaria Zaky**, Ghada Abdelrahman Ahmed* \\ \& Laila Mohamed Fathy Youssef***
}

\begin{abstract}
*Internal Medicine Department, Faculty of Medicine, Ain Shams University

**Tropical Medicine Department, Faculty of Medicine, Ain Shams University

*** Pour Toi Center Cairo, Egypt.
\end{abstract}

Corresponding author

Laila Mohamed Fathy Youssef

Mobile: (+2) 01065501755

E.mail:

lailaafify@icloud.com

Received: 29/7/2021

Accepted: 20/9/2021

Online ISSN: 2735-3540

\begin{abstract}
:
Background: Irritable bowel syndrome (IBS) is a chronic functional gastrointestinal disorder characterized by abdominal pain with altered bowel habits. Proposed etiological mechanisms include altered gastrointestinal motility, visceral hypersensitivity, abnormal pain processing in the central nervous system, low grade inflammation, following enteric infection, altered psychological state and imbalances in the intestinal flora. Discovering the possible associating factors enables us to provide a better quality of life for IBS patients.
\end{abstract}

Aim of the Work: To study the associated factors with irritable bowel syndrome among medical Ain Shams university students.

Subject and Methods: In the first phase a cross-sectional study was conducted on students from database of the Nutritional Assessment of Medical Students of Ain Shams University Project. 1225 students aged between 19 and 24 years during the period of April 2018 and April 2019 were obtained from the database and interviewed. After applying the inclusion and exclusion criteria, only 73 students were suffering from IBS according to criteria of Rome IV then a second phase was conducted by selecting a comparative normal group randomly to conduct a comparative study between those suffering from IBS and normal healthy students to find out the potentially associated factors among students. Data on participants' diet, life style, anthropometry and biochemical investigations including $C B C$, iron profile and vitamin D levels were gathered.

Results: The associated factors statistically significant with IBS were increased intake of stimulating drinks and brown bread, increased fatigue, irritability and behavioral changes, increased muscle cramps and iron deficiency aneamia.

Conclusion: Medical students are likely to be subjected to substantial amount of stress and anxiety that are the major factors for IBS, along other factors. More studies are needed to further evaluate those factors and to implement preventative strategies to control the disease and enhance the quality of life of medical students.

Keywords: Irritable bowel syndrome; NAMES-ASU; Constipation-predominant

\section{INTRODUCTION:}

Irritable bowel syndrome (IBS) is a chronic functional gastrointestinal disorder characterized by abdominal pain or discomfort, in association with altered bowel habit. The natural history of the condition is a relapsing and remitting one ${ }^{[1]}$, with most sufferers experiencing episodes of exacerbation of symptoms and other periods where symptoms are less troublesome, or even quiescent. 


\section{Wesam Ahmed Ibrahim, et al.,}

The prevalence of IBS in the general population varies between 5 and $20 \%$ in cross-sectional surveys, and may be influenced by the demographics of the population under study. For example, in our study it is $7 \%$, IBS is commoner in females ${ }^{[2]}$ and younger ${ }^{[3]}$.

Prevalence is also higher in those with coexisting functional gastrointestinal diseases, particularly dyspepsia and gastrooesophageal reflux disease $\mathrm{e}^{[4]}$, and other functional disorders, such as fibromyalgia and chronic fatigue ${ }^{[5]}$.

It seems unlikely that there is a single unifying explanation for these symptoms. It is more plausible that a combination of factors contributes to the abdominal pain and disturbance in bowel habit. Proposed etiological mechanisms that may be involved in the disorder include altered gastrointestinal motility, visceral hypersensitivity, abnormal pain processing in the central nervous system, dysregulated intestinal immunity ${ }^{[6]}$, low-grade inflammation and altered gastrointestinal permeability following enteric infection, imbalances in intestinal flora and altered psychological state $^{[7]}$.

Irritable bowel syndrome also aggregates in families but whether this is due to genetic factors, shared upbringing, or both is unclear. Diagnosing IBS can be challenging for the physician, due to the potential for overlap between the symptoms that sufferers report and those of organic gastrointestinal conditions such as coeliac disease, small intestinal bacterial overgrowth, bile acid diarrhea, exocrine pancreatic insufficiency, inflammatory bowel disease and even colorectal cancer. Attempts to identify a biomarker for the condition have, to date, been unsuccessful ${ }^{[8]}$.

Medical treatment for IBS is considered to be unsatisfactory, with patients representing a significant financial burden. Despite this, there is evidence that fiber, antispasmodic drugs, antidepressants and probiotics are all more effective than placebo in the short-term therapy of IBS, although no single medical treatment has been demonstrated to alter the long-term natural history of the disorder ${ }^{[9]}$.

The definition and classification of IBS are both of paramount importance to the management of sufferers. Accurate definitions allow physicians to diagnose IBS with confidence, but physicians should be discouraged from over-investigating young patients who are otherwise well and clearly meet these criteria, and in whom the diagnostic yield of such investigations is likely to be low, hence reducing the costs and also avoid unnecessary surgery in patients with IBS ${ }^{[10]}$.

Classification of IBS according to symptoms allows the tailoring of therapy according to the predominant symptom reported by the patient, as well as the assessment of which of the existing, as well as novel, treatments are effective in particular subgroups of patients. As a result, in the latest Rome definition it is possible to classify IBS into diarrhea-predominant (IBSD), constipation-predominant (IBS-C), or those who fluctuate between the two, socalled mixed IBS (IBS-M) ${ }^{[11]}$.

This is a useful approach for several reasons. Firstly, it allows the targeting of therapies by the physician towards the most troublesome by the patient. Secondly, it aids the development of new pharmaceutical agents to treat these symptom-reported subgroups discretely. Thirdly, it allows the investigation of patients according to these subcategories in order to explore possible underlying pathophysiological mechanisms, towards which future therapies may be directed ${ }^{[12]}$.

Mental balance, the ability to cope with stress, as well as physical activity and fitness, remain key elements in maintaining physical and mental health. Based on research in 


\section{Potentially Associated Factors With Irritable Bowel Syndrome Among Medical Ain Shams University Students}

various fields of medicine, bearing in mind the overall pro-health effect, it should be assumed that they also bring added benefits to the treatment of patients with IBS ${ }^{[13]}$.

Taking into account the symptoms reported by patients (up to $80 \%$ of respondents say the occurrence of symptoms is dependent on their current diet) and the available test results, it can be assumed that diet is important in the occurrence of symptoms of irritable bowel syndrome ${ }^{[14]}$. Many trials have shown that efficacy of probiotics is strain-dependent. Therefore, in this analysis, although probiotics in general were also considered ${ }^{[15]}$.

Functional gastrointestinal tract disorders have been considered for several years as a manifestation of disorders of interactions of the brain-gut-microbiota axis. Abnormalities leading to the occurrence of abdominal symptoms include disturbances of nerve conduction which result in hypersensitivity to stimuli and a hyperreactive neuronal response. In patients with IBS, emotional disorders often occur (mood disorders,

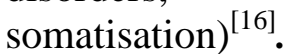
depression, anger,

\section{AIM OF THE WORK:}

The aim is to study the associated factors with irritable bowel syndrome among medical Ain Shams university students.

\section{SUBJECT AND METHODS:}

This study was conducted through 2 phases:

$\mathbf{I}^{\text {st }}$ phase: Cross sectional study was conducted on all 1225 students from database of the Nutritional Assessment of Medical Students of Ain Shams University (NAMES-ASU) Project to measure the prevalence of irritable bowel syndrome among all students. $2^{\text {nd }}$ phase: Comparative study was conducted between 2 groups, group (A): 73 students suffering from irritable bowel syndrome and group (B): 75 normal students to find out the potentially associated factors with irritable bowel syndrome among Egyptian medical students in Ain Shams University.

Study Setting: The study was conducted in faculty of Medicine Ain Shams University.

Study Period: The study took place from April 2018 to April 2019.

Study Population: Medical students participated in the Nutritional Assessment of Medical Students of Ain Shams University (NAMES-ASU) Project which was designed to evaluate the nutritional status of the undergraduate medical students.

Inclusion Criteria: Students of faculty of medicine ASU with age above 18 years old who fulfilled Rome IV criteria for IBS diagnosis.

Exclusion Criteria: 1) History of long term use of certain medications as aspirin and antidepressants during the last 6 months. 2) History suggestive of other gastrointestinal trouble as peptic ulcer or Irritable Bowel Disease (IBD). 3) Abdominal surgeries. 4) Diabetes mellitus. 5) Thyroid problems.

\section{Case Definition of IBS:}

According to ROME IV criteria [17] IBS is diagnosed if there is recurrent abdominal pain, on average, at least 1 day per week in the last 3 months associated with 2 or more of the following criteria: Related to defecation, associated with a change in frequency of stool and Associated with a change in form (appearance) of stool.

Sampling Method: This is a convenience sample based on volunteers from the medical students at Ain Shams University. Students were approached using different methods including facebook pages, 
web site of the faculty and face to face announcements has been also used.

Sample Size: All students from the database of the Nutritional Assessment of Medical Students of Ain Shams University (NAMES-ASU) Project. 73 students were obtained from the database, interviewed and applied on them the exclusion criteria as shown. All IBS cases were taken and a comparative non-IBS group was selected randomly from all students (70 for each group) to identify potentially associated factors with irritable bowel syndrome among Egyptian medical students in Ain Shams University.

\section{Study Tools and Methods:}

All cases and controls participants were subjected to:

- Interview questionnaire including data pertaining name, age, sex, study grade, past medical history and family history

- 24 hour dietary recall

- General clinical examination

- Anthropometric measures of weight, height, Body Mass Index(BMI), waist, circumference, and waist hip ratio, and bioelectric impedance segmental analysis using InBody 770

- Biochemical Investigations including complete blood count (CBC), glycatedheamoglobin (HbA1C), iron profile, and 25 hydroxy vitamin D levels.

- Data was collected from 1225 students over 3 months.

\section{History taking using:}

A structured Arabic language questionnaire was completed from the participating students inquiring about sociodemographic data, past and family history of any diseases as hypertension, diabetes mellitus, cancer, obesity or Alzheimer special habit like smoking, physical exercising, exposure to sunlight and number of hours of sleep. Nutritional status including weight changes, appetite changes, fluid intake, activity level and drug or vitamin intake was also collected. Female participants were asked about gynecological and obstetric history (age of menarche, length of cycle, duration of menstruation, and amount of bleeding), Symptoms of any chronic disease such as GI, chest, musculoskeletal, renal, cardiovascular and neuropsychiatric symptoms were also asked about.

\section{Clinical examination General appearance:}

Vital signs were checked

Systolic blood pressure-Diastolic blood pressure: Measured blood pressure (BP): BP measurement was done using sphyngmomanometer by same person. With the participant in a relaxed sitting position $\mathrm{BP}$ will be measured in right arm using auscultatory method (National High Blood Pressure Education Program working group on high blood pressure in adolescents 2004).

Examine: hair, skin turgor, eye, teeth, gum, lips, neck, tongue and parotid.

Signs of nutritional deficiencies from head to toe Clinical examination of cardiovascular, chest, abdominal and neurological system.

Anthropometric evaluation: Anthropometric measures, Weight (kgs), Height (cms), BMI, Waist circumference (cms), Hip circumference $(\mathrm{cm})$, Waist to hip ratio and Fat and muscle composition.

24-hours Dietary recall: The 24 hour recall was analyzed for 83 anemic female students as well as 84 non anemic female students. This food composition analysis was done by the National Nutritional Institute to calculate the amount of iron taken in their food intake.

Food frequency questionnaire: Dietary habits such as intake frequency of breakfast, number of meals taken per day, type of snacks taken between meals 


\section{Potentially Associated Factors With Irritable Bowel Syndrome Among Medical Ain Shams University Students}

frequency of intake of fresh vegetables, cooked vegetables, fresh fruits, processed food, junk food, carbonated drinks, stimulant drinks, type of bread (Baladi or White), rice or macaroni, whole grains, milk products, meat and poultry, fish and sea foods, eggs, legumes, vegetable oils, hydrogenated oils, butter were all taken.

\section{Biochemical investigations:}

1. Sample collection Samples were collected from each patient under complete aseptic conditions, using sterile vacutainers. Two $\mathrm{mL}$ peripheral blood samples were obtained on ethylenediamine tetra-acetic acid, dipotassium salt (K2-EDTA) in vacutainer tubes (final concentration of $1.5 \mathrm{mg} / \mathrm{mL}$ ) for CBC and preparation of Leishman-stained PB smears. Two $\mathrm{mL}$ of peripheral blood were collected and used for iron profile.

2. Laboratory investigations:

- Complete blood count (CBC) using Medonic cell counter (M series, Sweden), with examination of Leishman stained PB smears for full differential leucocyte count. )

- Iron profile (iron, total iron binding capacity (TIBC) using humalyzer 3000 (Human) spectrophotometer and ferritin using Accubind ELISA microwells (Monobind Inc., USA) .

- HBA1c using the Uniten HBA1c test kit with the UNT5000 Analyzer.
- 25 hydroxy vitamin D blood level using Orgentec Enzyme Linked immunosorbent assay.

- High sensitivityc-reactive protein (CRP) using ELISA kit.

\section{Statistical analysis and Prediction Score development:}

Analysis of data was done using SPSS program version 23 . To describe the studied sample, quantitative data were presented as minimum, maximum, mean and standard deviation. Qualitative data were presented as number and percentage. Student t test was used to compare quantitative data between two independent groups and Chi-Square test (or Fisher Exact test) were used to compare qualitative data between different groups. Logistic regression analysis was done to identify risk factors for IBS among study participants. $\mathrm{P}$ value $<0.05$ was considered statistically significant, P-value $<0.001$ was considered as highly significant and P-value $>0.05$ was considered insignificant.

\section{Ethical Considerations:}

All students signed an informed consent after explaining to them the objective of the study. Anonymity and confidentiality were ensured .Ethical Approval was obtained from Ain Shams Faculty of Medicine ethical committee. Obtained from each student and their legal guardians before enrolment in this study after explaining the aim of the study and all the procedures that were done. Privacy and confidentiality were concerned. Aproval was obtained from the ethical committee. Follow up of medical students was proceeded on weekly base by phone or whatsapp. 


\section{RESULTS:}

Description of study participants:

Table (1): Demographic data

\begin{tabular}{|c|c|c|c|c|c|}
\hline & $\mathrm{N}$ & Min. & Max. & Mean & SD \\
\hline Age in years & 148 & 18.00 & 28.04 & 22.29 & 1.84 \\
\hline \multicolumn{2}{|c|}{ Gender } & Male & \multicolumn{2}{|c|}{31} & \multicolumn{2}{c|}{$20.9 \%$} \\
\cline { 2 - 6 } & Female & \multicolumn{2}{|c|}{117} & \multicolumn{2}{c|}{$79.1 \%$} \\
\hline
\end{tabular}

This table describes the age of the participants which was between 18 and 28 years old, it also describes the gender of the participants which shows 117 female and 31 males.

Table (2): IBS diagnostic symptoms and criteria among cases.

\begin{tabular}{|c|c|c|c|}
\hline \multicolumn{2}{|c|}{} & $\mathbf{N}$ & $\%$ \\
\hline recurrent abdominal pain last three & Yes & 70 & $100 \%$ \\
\cline { 2 - 4 } months & No & 0 & $0 \%$ \\
\hline \multirow{3}{*}{ frequency of pain per week } & $\mathbf{1 . 0 0}$ & 12 & $16.4 \%$ \\
\cline { 2 - 4 } & $\mathbf{2 . 0 0}$ & 32 & $43.8 \%$ \\
\cline { 2 - 4 } & $\mathbf{3 . 0 0}$ & 11 & $15.1 \%$ \\
\cline { 2 - 4 } & $\mathbf{4 . 0 0}$ & 8 & $11.0 \%$ \\
\cline { 2 - 4 } & $\mathbf{5 . 0 0}$ & 3 & $4.1 \%$ \\
\hline \multirow{2}{*}{ pain with defecation } & $\mathbf{7 . 0 0}$ & 7 & $9.6 \%$ \\
\hline associated with change in stool & yes & 67 & $91.8 \%$ \\
\cline { 2 - 4 } frequency & no & 6 & $8.2 \%$ \\
\hline \multirow{2}{*}{ associated with change in stool form } & no & 24 & $67.1 \%$ \\
\cline { 2 - 4 } & yes & 68 & $32.9 \%$ \\
\hline
\end{tabular}

This table shows prevalence of IBS symptoms according to Rome IV among cases. $100 \%$ of the cases suffered from recurrent abdominal pain in the last 3 months of which $91.8 \%$ suffered from pain with defecation, $67.1 \%$ suffered from change in stool frequency while $93.2 \%$ suffered from change in form of stool. Frequency of abdominal pain was once per

week in $16.4 \%$ of the cases, twice per week in $43.8 \%$ of the cases, trice per week in $15.1 \%$ of the cases, 4 times per week in $11 \%$ of the cases, 5 times per week in $4.1 \%$ of the cases and 7 times per week in $9.6 \%$ of the cases.

Comparison between cases and controls (factors associated with IBS):

Table (3): Comparison between cases and controls regarding demographic data

\begin{tabular}{|c|c|c|c|c|c|c|c|}
\hline & \multicolumn{2}{|c|}{$\begin{array}{c}\text { Cases } \\
(\mathrm{N}=73)\end{array}$} & \multicolumn{2}{|c|}{$\begin{array}{c}\text { Controls } \\
(\mathrm{N}=75)\end{array}$} & \multirow[t]{2}{*}{$t^{*}$} & \multirow[t]{2}{*}{$\mathrm{P}$ value } \\
\hline & & Mean & SD & Mean & SD & & \\
\hline \multicolumn{2}{|c|}{ Age in years } & 22.28 & 1.77 & 22.30 & 1.92 & 0.07 & $0.94 \mathrm{NS}$ \\
\hline & & $\mathrm{N}$ & $\%$ & $\mathrm{~N}$ & $\%$ & $X^{2^{* *}}$ & $\mathrm{P}$ value \\
\hline \multirow{2}{*}{$\underset{\stackrel{D}{0}}{\stackrel{\dot{D}}{0}}$} & Male & 19 & $26.0 \%$ & 12 & $16.0 \%$ & \multirow{2}{*}{2.25} & \multirow{2}{*}{$0.13 \mathrm{NS}$} \\
\hline & Female & 54 & $74.0 \%$ & 63 & $84.0 \%$ & & \\
\hline
\end{tabular}

*Student $\mathrm{t}$ test $* *$ Chi square test 


\section{Potentially Associated Factors With Irritable Bowel Syndrome Among Medical Ain Shams University Students}

Demographic data is matched regarding age and gender in IBS patients compared to healthy controls showing mean age of cases was 22.28 years old while it was 22.30

Table (4): Comparison between cases and controls regarding anthropometric measures

\begin{tabular}{|c|c|c|c|c|c|c|}
\hline & \multicolumn{2}{|c|}{ Cases } & \multicolumn{2}{c|}{ Controls } & \multirow{2}{*}{$t^{*}$} & \multirow{2}{*}{ P value } \\
\cline { 2 - 5 } & Mean & SD & Mean & SD & & \multirow{2}{*}{$0.64 \mathrm{NS}$} \\
\hline Height $(\mathrm{cm})$ & 162.98 & 9.20 & 163.62 & 7.46 & 0.46 & $0.68 \mathrm{NS}$ \\
\hline Weight $(\mathrm{kg})$ & 67.71 & 14.10 & 66.75 & 14.12 & 0.41 & $0.39 \mathrm{NS}$ \\
\hline BMI $(\mathrm{kg} / \mathrm{m} 2)$ & 25.67 & 6.32 & 24.87 & 4.79 & 0.86 & $0.68 \mathrm{NS}$ \\
\hline Waist $(\mathrm{cm})$ & 81.14 & 9.85 & 80.45 & 10.77 & 0.41 & $0.05 \mathrm{~S}$ \\
\hline Hip $(\mathrm{cm})$ & 102.19 & 8.81 & 99.12 & 10.01 & 1.97 & $0.09 \mathrm{NS}$ \\
\hline Waist/Hip ratio & .79 & .06 & .81 & .06 & 1.71 & 0 \\
\hline
\end{tabular}

*Student $\mathrm{t}$ test

This table shows a statistically significant higher mean hip circumference in

IBS cases compared to normal control participants.

among controls, also shows that we had 19 male and 54 female cases while we had 12 male and 63 female controls.

Table (5): Comparison between cases and controls regarding GIT symptoms

\begin{tabular}{|c|c|c|c|c|c|c|c|}
\hline & & \multicolumn{2}{|c|}{ Cases } & \multicolumn{2}{|c|}{ Controls } & \multirow{2}{*}{$X^{2^{*}}$} & \multirow{2}{*}{$\mathrm{P}$ value } \\
\hline & & $\mathrm{N}$ & $\%$ & $\mathrm{~N}$ & $\%$ & & \\
\hline \multirow{2}{*}{ Taste Changes } & yes & 4 & $5.5 \%$ & 5 & $6.7 \%$ & \multirow{2}{*}{$\begin{array}{c}0.09 \\
\mathrm{FE}\end{array}$} & \multirow{2}{*}{$1.00 \mathrm{NS}$} \\
\hline & no & 69 & $94.5 \%$ & 70 & $93.3 \%$ & & \\
\hline \multirow{2}{*}{ Heart Burn } & yes & 38 & $52.1 \%$ & 22 & $29.3 \%$ & \multirow{2}{*}{7.92} & \multirow{2}{*}{$0.01 \mathrm{HS}$} \\
\hline & no & 35 & $47.9 \%$ & 53 & $70.7 \%$ & & \\
\hline \multirow{2}{*}{ Diarrhea } & yes & 26 & $35.6 \%$ & 11 & $14.7 \%$ & \multirow{2}{*}{8.66} & \multirow{2}{*}{$0.003 \mathrm{HS}$} \\
\hline & no & 47 & $64.4 \%$ & 64 & $85.3 \%$ & & \\
\hline \multirow{2}{*}{ Constipation } & yes & 47 & $64.4 \%$ & 18 & $24.0 \%$ & \multirow{2}{*}{24.49} & \multirow{2}{*}{$<0.001 \mathrm{HS}$} \\
\hline & no & 26 & $35.6 \%$ & 57 & $76.0 \%$ & & \\
\hline
\end{tabular}

*Chi square test (FE: Fisher Exact)

This table shows a statistically significant higher mean regarding heart burn, diarrhea and constipation in IBS cases

in comparison with the normal control participants.

Table (6): Comparison between cases and controls regarding family history of hypertention, dyslipidemia, cancer, obesity and Alzheimer.

\begin{tabular}{|c|c|c|c|c|c|c|c|}
\hline & & \multicolumn{2}{|c|}{ Cases } & \multicolumn{2}{|c|}{ Controls } & \multirow{2}{*}{$\mathrm{X}^{2^{*}}$} & \multirow{2}{*}{$P$ value } \\
\hline & & $\mathrm{N}$ & $\%$ & $\mathrm{~N}$ & $\%$ & & \\
\hline \multirow{2}{*}{ Hypertention } & yes & 41 & $56.2 \%$ & 48 & $64.0 \%$ & \multirow{2}{*}{0.95} & \multirow{2}{*}{$0.33 \mathrm{NS}$} \\
\hline & no & 32 & $43.8 \%$ & 27 & $36.0 \%$ & & \\
\hline \multirow{2}{*}{ Dyslipidemia } & yes & 27 & $37.0 \%$ & 15 & $20.0 \%$ & \multirow{2}{*}{5.25} & \multirow{2}{*}{$0.02 \mathrm{~S}$} \\
\hline & no & 46 & $63.0 \%$ & 60 & $80.0 \%$ & & \\
\hline \multirow{2}{*}{ Cancer } & yes & 23 & $31.5 \%$ & 22 & $29.3 \%$ & \multirow{2}{*}{0.08} & \multirow{2}{*}{$0.77 \mathrm{NS}$} \\
\hline & no & 50 & $68.5 \%$ & 53 & $70.7 \%$ & & \\
\hline \multirow{2}{*}{ Obesity } & yes & 30 & $41.1 \%$ & 25 & $33.3 \%$ & \multirow{2}{*}{0.96} & \multirow{2}{*}{$0.33 \mathrm{NS}$} \\
\hline & no & 43 & $58.9 \%$ & 50 & $66.7 \%$ & & \\
\hline \multirow{2}{*}{ Alzheimer } & yes & 10 & $13.7 \%$ & 6 & $8.0 \%$ & \multirow{2}{*}{1.25} & \multirow{2}{*}{$0.26 \mathrm{NS}$} \\
\hline & no & 63 & $86.3 \%$ & 69 & $92.0 \%$ & & \\
\hline
\end{tabular}

*Chi square test (FE: Fisher Exact)

This table shows a statistically significant higher family history of

dyslipidemia in IBS cases compared to normal control participants. 


\section{DISCUSSION:}

Irritable bowel syndrome (IBS) is one of the most common and potentially disabling gastrointestinal disorders characterized by pain in abdomen, bloating, and alteration in a person's bowel habits, but without any organic pathology. Traditionally, in practical work, IBS was diagnosed by exclusion, but recently, Rome criteria was used as a golden tool for diagnosis of IBS in researches and clinical work. According to Rome IV, IBS can be classified as either diarrheapredominant (IBS-D), constipationpredominant (IBS-C), or with alternating stool pattern (IBS-A) or pain-predominant (Richards et al., 2020).

The prevalence of IBS varies from 5.7 to $34 \%$ worldwide, with a wide variation based on the tool used. According to Rome IV criteria, Western population have higher prevalence of IBS (ranges from 10 to 15\%) than Asian ones (ranges from 1 to 10\%). Arab countries are among the least studied populations in the world. A recent meta-analysis of the global prevalence of IBS revealed no studies done from any Arab country. However, limited data are available on IBS in some countries, including an Egyptian study conducted in an urban area in China governorate which revealed high prevalence rate of $34.2 \%$ among the studied group. Another study conducted in Korea showed a prevalence of $11.4 \%$ (Szahwińska et al., 2020).

Anxiety and depression can affect many university students particularly those studying medicine. They are under constant stress due to the long duration of their study with high work overload and mental exhaustion due to numerous exams. A recent Chinese study compared the prevalence of IBS among students in different universities and found that medical students had the highest level of IBS compared to engineering and science students. In Saudi Arabia, a study conducted on medical students and interns in Jeddah reported a prevalence of IBS of $31.8 \%$. In Egypt, information on the prevalence of IBS and its associated factors among university students is deficient; a recent Chinese study reported $29.2 \%$ prevalence rate among the general population (Yao et al., 2020).

This cross-sectional nutritional survey a nested case-control study was conducted at the Faculty of Medicine Ain Shams University and Ain Shams University hospitals including 1225 students. The duration of the study ranged from 6-12 months.

\section{The main results of this study were:}

There was no statistically significant difference between cases and controls as regards age and sex, cases and controls were matched.

The mean age in the study of Elhosseiny et al., 2019 was 20.69 \pm 3.99. This study revealed a significant difference regarding the academic year, being $52.8 \%$ in junior years (1st, 2nd, and 3rd years), and $47.2 \%$ in senior years. This difference may be related to the stress facing the new attendants to the faculty. Some studies reported that it is more common among age groups below 25 years. However, typical medical students' age range does not vary significantly in different medical schools, which devalues the comparison based on this factor. A study from Jeddah, Saudi Arabia conducted by Ibrahim et al., 2013 showed that the prevalence of IBS was higher in senior years, which was attributed to the higher study load rather than the difference in age.

IBS creates an incredible cost for both patients and the health care system. It is one of the commonest disorders diagnosed by gastroenterologists. There is a large part of the population suffering from IBS while only some seek health care in the absence of curative therapy. The prevalence of IBS usually varies significantly between countries 


\section{Potentially Associated Factors With Irritable Bowel Syndrome Among Medical Ain Shams University Students}

and depends on the diagnostic criteria used (Moayyedi et al., 2019).

The present study showed that there was statistically significant lower mean pulse in cases with IBS compared to normal control participants. It also shows statistically significant lower mean as regards to dry hair, brittle hair, ridged nails, pale nails and rough skin in cases with IBS compared to normal control participants. There was statistically significant lower mean regarding eye pallor, eye dryness and gum bleeding in IBS cases compared to normal control participants and statistically significant lower mean regarding dry lips in IBS cases compared to the normal control participants, while it shows higher mean regarding whitish tongue in IBS cases compared to the normal control participants. There was statistically significant higher mean hip circumference in IBS cases compared to normal control participants and no statistically significant difference as regard weight, height and BMI.

In contrary with our results, study of Ibrahim et al., 2013 as they revealed that students who practiced physical exercise had a significantly lower prevalence of IBS than others (Odds Ratio $\quad(\mathrm{OR})=0.59 ; \quad 95 \%$ Confidence Interval(CI): 0.42-0.85). Morbidly obese students and students who slept less hours per day $(<8 \mathrm{~h} /$ day $)$ had a higher prevalence of IBS compared to other students $(\mathrm{p}<0.05)$. Similarly, those who obtained higher Grade Point Average (GPA) had slightly higher rates of IBS compared to others.

The current study showed that there was statistically significant higher mean regarding heart burn, diarrhea and constipation in IBS cases in comparison with the normal control participants. There was no statistical significance regarding symptoms of chest symptoms in IBS cases compared to normal control participants. There was high statistically significant higher mean iron deficiency anemia in IBS cases compared to normal control participants. There was no statistical significance as regards symptoms of renal diseases in IBS cases in comparison with normal control participants. There was statistically significant higher mean regarding muscle cramps in IBS cases compared to normal control participants.

Our results were supported by study of Elhosseiny et al., 2019 as they demonstrated that no statistically significant difference regarding other health problems characteristics.

In the study in our hands, there was statistically significant higher behavioral changed in IBS cases compared to normal control participants. It also shows high statistically significant higher irritability, fatigue and muscle cramps in IBS cases in comparison with normal control participants.

The major feature of fibromyalgia is chronic widespread pain and is typically accompanied by a range of symptoms including fatigue, headache, sleep and cognitive disturbances, as well as digestive disorders, including IBS. It is thought that both fibromyalgia and FGID are attributable to sympathetic dysfunction with resultant central sensitisation. Both conditions were recently categorised as 'Central Sensitivity Syndromes'. While a common etiology has been proposed, there is currently no compelling evidence to support a targeted intervention (Erdrich et al., 2020).

Physical and psychological stresses are considered major contributing factors to IBS etiology. The exact mechanism is not clear, but it is believed that the changes in CNS in response to psychological and physical stressors lead to colonic spasms, which results in the manifestation of IBS symptoms. Medical students are likely to be under a lot of stress due to the tremendous academic load. In the study of Elhosseiny et al., 2019, they assessed psychological problems and found that almost two-thirds of our students with IBS were having emotional stress in their past 6 
months, $32.9 \%$ were anxious and $26.1 \%$ were depressed, $26.3 \%$ were borderline anxious and $27.2 \%$ were borderline depressed. The current results showed a significant difference regarding anxiety, being higher in IBS patients, especially the IBS-D. Depression showed highly significant difference in relation to IBS subtypes, being higher in the diarrhea predominant subtype too. Similarly, a study in Jeddah, Saudi Arabia carried out by Ibrahim et al., 2013, reported that $40.1 \%$ of students with IBS had morbid anxiety, and $41.9 \%$ had morbid depression, compared to IBS students with borderline depression (29.5\%) and with no depression (31.5\%). Similar results were also obtained from King Saud University in Saudi Arabia and from Malaysian studies (Tan et al., 2003, Al-Turki et al., 2011). A Pakistani study showed that $55.8 \%$ of IBS causes were associated with stress (Naeem et al., 2012). The Malaysian study also reported higher rates of depression in IBS students (Tan et al., 2003). Okami et al., 2011 in Japan also reported a significantly higher level of anxiety and depression among IBS students.

Emotional stress was common in participants with IBS and significantly predicted IBS prevalence. The role of stress in IBS is well-established. Evidence from clinical and experimental studies showed that emotional stress significantly impacts intestinal sensitivity, secretion, motility, and permeability, and the underlying mechanism correlates with activation of mucosal immunity, alterations in central and peripheral neurons, and gastrointestinal microbiota. As a result of stress, alterations in neuroendocrine-immune pathways act on the gut-brain axis and cause or exaggerate symptoms of IBS. IBS is a stress-sensitive condition; therefore, treatment methods should focus on managing stress and stressinduced responses (Qin et al., 2014).

Furthermore, Alzahrani et al., 2018 revealed that the prevalence of IBS among participants who have family history of the disease was significantly higher $(\mathrm{p}<0.001)$ than that among participant who don't have family history of the disease.

Heredity plays an important role in IBS development (Canavan et al., 2014). In the study of AlButaysh et al., 2020, having a first-degree relative with IBS was significantly associated with IBS symptoms.

Eating habits and dietary balance can play a very important role in the development and severity of IBS-related symptoms. These factors are particularly important in students as they are more likely to be less cautious with their diet. Items discussed were chewing well; having breakfast; drinking plenty of fluids; favoring fresh food like fruits, vegetables, nuts, fish, and dairy products; consuming excess spicy or processed food; and drinking excess coffee or tea (Whitehead \& Drossman, 2010).

The current study showed that there was no statistical significance as regards to nutritional status of IBS cases compared to normal control participants. There was statistically significant higher mean regarding monthly intake of stimulating drinks and brown bread in IBS cases compared to normal control participants. There was no statistical significance regarding fod map monthly intake in IBS cases compared with normal control participants.

Regarding special habits, unexpectedly, smoking was not found to be associated with high IBS prevalence and only $10 \%$ of IBS students were smokers. A study from Jeddah, Saudi Arabia showed similar results with no significant association between smoking and having IBS (Ibrahim et al., 2013). However, a study from India reported an association between cigarettes smoking and IBS (Basandra \& Bajaj, 2014). Regular exercise as a lifestyle habit was significantly protective against developing IBS in the study of Elhosseiny et al., 2019 and few 


\section{Potentially Associated Factors With Irritable Bowel Syndrome Among Medical Ain Shams University Students}

other studies. Further, $71.9 \%$ of students with IBS were not performing regular exercise in this study. A study from Saudi Arabia found that IBS prevalence was higher $(37.3 \%)$ among students who did not exercise regularly compared to those who did (26.1\%) (Ibrahim et al., 2013). Similarly, a study in Japan reported that students with IBS were performing less exercise than students with no IBS (Okami et al., 2011).

The present study showed that as regard Logistic regression analysis for risk factors of IBS, female gender and IronDeficiencyAnemia was dependent risk factor for IBS.

Our study did not show statistical significance regarding gender of IBS patients compared to healthy controls.

Our results were not supported by study of AlButaysh et al., 2020 as they revealed that the prevalence of IBS was higher among females than among males, with a female to male ratio of $1.27: 1$. This is in agreement with previous reports that found a female predominance in IBS prevalence (Heidelbaugh et al., 2015, Sperber et al., 2017). In a systemic review and metaanalysis of 55 studies including 162,543 subjects, women showed a higher prevalence of IBS than men (Chang et al., 2002). Possible explanations for this difference include physiologic differences and different medical care-seeking behaviors (Kim et al., 2018).

\section{Conclusion:}

This study concluded that by comparing cases and controls regarding their dietary habits we found no significant difference except in their consumption of stimulating drinks and brown bread which appeared to be more excessive among the cases which rises a concern that they might be a serious risk factor.

\section{REFERENCES}

1. Ford A, Talley N, Spiegel B, FoxxOrenstein A, Schiller L, Quigley E, Moayyedi P. (2008): Effect of fibre, antispasmodics, and peppermint oil in the treatment of irritable bowel syndrome: systematic review and meta-analysis. BMJ.;337: a2313.

2. Sperber A, Shvartzman P, Friger M, Fich A. (2005): Unexpectedly low prevalence rates of IBS among adult Israeli Jews. Neurogastroenterol Motil.;17(2):207-11.

3. Hungin A, Chang L, Locke G, Dennis E, Barghout V. (2005): Irritable bowel syndrome in the United States: prevalence, symptom patterns and impact. Aliment Pharmacol Ther.; 21(11):1365-75.

4. Ford A, Moayyedi P. (2010): Metaanalysis: factors affecting placebo response rate in the irritable bowel syndrome. Aliment Pharmacol Ther.; 32(2):144-58.

5. Riedl A, Schmidtmann M, Stengel A, Goebel M, Wisser A, Klapp B, Mönnikes H. (2008): Somatic comorbidities of irritable bowel syndrome: a systematic analysis. J Psychosom Res.; 64(6):573-82.

6. Chadwick V, Chen W, Shu D, Paulus B, Bethwaite P, Tie A, Wilson I. (2002): Activation of the mucosal immune system in irritable bowel syndrome. Gastroenterology; 122(7):1778-83.

7. Kassinen A, Krogius-Kurikka L, Mäkivuokko H, Rinttilä T, Paulin L, Corander J, Malinen E, Apajalahti J, Palva A. (2007): The fecal microbiota of irritable bowel syndrome patients differs significantly from that of healthy subjects. Gastroenterology.;133(1):24-33.

8. Lembo A, Zaman M, Jones M, Talley N. (2007): Influence of genetics on irritable bowel syndrome, gastro-oesophageal reflux and dyspepsia: a twin study. Aliment Pharmacol Ther;25(11):1343-50

9. Moayyedi P, Ford A, Talley N, Cremonini F, Foxx-Orenstein A, Brandt L, Quigley E. (2010): The efficacy of probiotics in the treatment of irritable bowel syndrome: a systematic review. Gut.;59(3):325-32. 


\section{Wesam Ahmed Ibrahim, et al.,}

10. Erdrich S, Hawrelak JA, Myers SP, Harnett JE. (2020): A systematic review of the association between fibromyalgia and functional gastrointestinal disorders. Therap Adv Gastroenterol.; 13:1756284820977402.

11. Berstad A, Hauso O, Berstad K, Berstad J. (2020): From IBS to ME - The dysbiotic march hypothesis. Med Hypotheses; 140:109648.

12. Marciani L, Cox E, Hoad C, Pritchard S, Totman J, Foley S, Mistry A, Evans S, Gowland P, Spiller R. (2010): Postprandial changes in small bowel water content in healthy subjects and patients with irritable bowel syndrome. Gastroenterology.; 138(2):469-77, 477.e1.

13. Longstreth G, Yao J. (2004): Irritable bowel syndrome and surgery: a multivariable analysis. Gastroenterology; 126(7):1665-73.

14. Schnabel L, Buscail C, Sabate J, Bouchoucha M, Kesse-Guyot E, Allès B, Touvier M, Monteiro C, Hercberg S, Benamouzig R, Julia C. (2018): Association Between Ultra-Processed Food Consumption and Functional Gastrointestinal Disorders: Results From the French NutriNet-Santé Cohort. Am J Gastroenterol.; 113(8):1217-1228.

15. Kabir M, Ishaque S, Ali M, Mahmuduzzaman M, Hasan M. (2011): Role of Saccharomyces boulardii in diarrhea predominant irritable bowel syndrome. Mymensingh Med J.;20(3):397401.

16. Dinan T, Quigley E, Ahmed S, Scully P, O'Brien S, O'Mahony L, O'Mahony S, Shanahan F, Keeling P. (2006): Hypothalamic-pituitary-gut axis dysregulation in irritable bowel syndrome: plasma cytokines as a potential biomarker? Gastroenterology.; 130(2):304-11.

17. Aziz I, Törnblom H, Palsson O, Whitehead W, Simrén M. (2018): How the Change in IBS Criteria From Rome III to Rome IV Impacts on Clinical Characteristics and Key Pathophysiological Factors. Am J Gastroenterol.; 113(7):1017-1025.

18. Szałwińska P, Włodarczyk J, Spinelli A, Fichna J, Włodarczyk M. (2020): IBSSymptoms in IBD Patients-Manifestation of
Concomitant or Different Entities. J Clin Med.;10(1):31.

19. Yao X, Yang Y, Zhang S, Shi Y, Zhang Q, Wang Y. (2020): The impact of overlapping functional dyspepsia, belching disorders and functional heartburn on anxiety, depression and quality of life of Chinese patients with irritable bowel syndrome. BMC Gastroenterol.; 20(1):209.

20. Elhosseiny, D, Mahmoud, N, \&Manzour, A. (2019): Factors associated with irritable bowel syndrome among medical students at Ain Shams University. Journal of the Egyptian Public Health Association, 94(1), $1-9$.

21. Moayyedi P, Andrews C, MacQueen G, Korownyk C, Marsiglio M, Graff L, Kvern B, Lazarescu A, Liu L, Paterson W, Sidani S, Vanner S. (2019): Canadian Association of Gastroenterology Clinical Practice Guideline for the Management of Irritable Bowel Syndrome (IBS). J Can Assoc Gastroenterol.;2(1):6-29.

22. Ibrahim $\mathrm{N}$, Battarjee $\mathrm{W}$, Almehmadi $\mathrm{S}$. (2013): Prevalence and predictors of irritable bowel syndrome among medical students and interns in King Abdulaziz University, Jeddah.Libyan J Med.; 8:21287.

23. Tan Y, Goh K, Muhidayah R, Ooi C, Salem O. (2003): Prevalence of irritable bowel syndrome in young adult Malaysians: a survey among medical students.J Gastroenterol Hepatol.; 18(12):1412-6.

24. Al-Turki Y, Aljulii M, Al Murayshid A, Al Omaish H, Al Daghiri K, Al Seleemi A, et al. (2011): Prevalence of irritable bowel syndrome among students in King Saud University, Riyadh, Saudi Arabia. World J Fam Med. 9:17-20.

25. Naeem S, Siddiqui E, Kazi A, Memon A, Khan S, Ahmed B. (2012): Prevalence and factors associated with irritable bowel syndrome among medical students of Karachi, Pakistan: a cross-sectional study. BMC Res Notes.; 5:255.

26. Okami Y, Kato T, Nin G, Harada K, Aoi W, Wada S, Higashi A, Okuyama Y, Takakuwa S, Ichikawa H, Kanazawa M, Fukudo S. (2011): Lifestyle and psychological factors related to irritable bowel syndrome in 


\section{Potentially Associated Factors With Irritable Bowel Syndrome Among Medical Ain Shams University Students}

nursing and medical school students.J Gastroenterol.; 46(12): 1403-10.

27. Qin H, Cheng C, Tang X, Bian Z. (2014): Impact of psychological stress on irritable bowel syndrome. World J Gastroenterol 20:14126-31.

28. Alzahrani T, Aljuaid A, Alharthi T, Aljabir A, Aziz L, Alshehri M, \&Masoodi, I. (2018): The prevalence and risk factors of irritable bowel syndrome among medical students and interns: results of a national survey in Saudi Arabia. 4(10).

29. Canavan C, West J, Card T. (2014): The epidemiology of irritable bowel syndrome. Clin Epidemiol.; 6:71-80.

30. AlButaysh O, AlQuraini A, Almukhaitah A, Alahmdi Y, Alharbi F. (2020): Epidemiology of irritable bowel syndrome and its associated factors in Saudi undergraduate students. Saudi J Gastroenterol.; 26(2):89-93.
31. Whitehead WE, Drossman DA. (2010): Validation of symptom-based diagnostic criteria for irritable bowel syndrome: a critical review. Am J Gastroenterol. 105(4):814-820.

32. Basandra S, Bajaj D. (2014): Epidemiology of Dyspepsia and Irritable Bowel Syndrome (IBS) in Medical Students of Northern India.J Clin Diagn Res.; 8(12):JC13-6.

33. Heidelbaugh J, Stelwagon M, Miller S, Shea E, Chey W. (2015): The spectrum of constipation-predominant irritable bowel syndrome and chronic idiopathic constipation: US survey assessing symptoms, care seeking, and disease burden.Am J Gastroenterol.; 110(4):580-7.

34. Chang L, Heitkemper M. 2002; Gender differences in irritable bowel syndrome. Gastroenterology. 123:1686-701.

35. Kim Y, Kim N. (2018): Sex-gender differences in irritable bowel syndrome. $\mathrm{J}$ NeurogastroenterolMotil. 24:544-58

\section{دراسة العوامل المحتمل ارتباطها بمتلازمة القولون العصبي لطلاب كلية الطب بجامعة عين شمس}

$$
\begin{aligned}
& \text { المقدمة: البيانات السابقة عن متلازمة القولون العصبي (IBS) و العو امل المرتبطة بها بين طلاب الجامعات نادرة }
\end{aligned}
$$

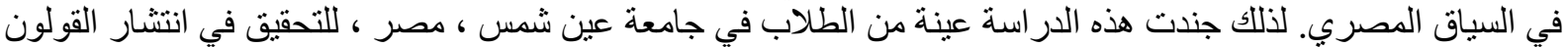

$$
\begin{aligned}
& \text { العصبي و العو امل المرتبطة بها وسد الفجوة البحثية المحددة. } \\
& \text { هدف العمل: در اسة العوامل المصاحبة لمتلازمة القولون العصبي لدى طلاب جامعة عين شمس الطبية. }
\end{aligned}
$$

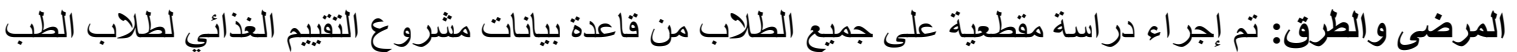

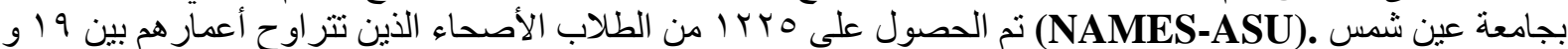

